\title{
Exploring the Application of Focusky-Based Presentation Media on Students' Creative Writing in Indonesian University Context
}

\author{
Sitti Rahmawati \\ sittirahmawati@umi.ac.id \\ Muliadi \\ muliadi@umi.ac.id \\ Universitas Muslim Indonesia
}

\begin{abstract}
Globally, students have long familiarized with utilizing a presentation program from Microsoft named PowerPoint, this program is good yet just not enough to stimulate students' creativity. It is necessary a program that can not only be used to display concepts but also be able to attract the attention of students while presenting. The program in question is Focusky, in addition to being easy to use the program is also able to display slides with zoom in-zoom out effect with friendly facilities and object effects galore making this program very suitable used by students in presenting their tasks in front of the class. This study employs a qualitative descriptive study by conducting data collection through books and other literature as the main object. Descriptive analysis method provides a clear, objective, systematic, analytical and critical picture and description of the application of focusky presentation media to the creative writing of Unuiversity students. Students in general, for example in the Faculty of Literature UMI do not have the same information technology capabilities (evenly) where there are those capable while some who are less in designing presentations. Hence, utilizing focusky will help students who could make creative presentations media to the best of their abilites. Focusky-based presentation acts as an alternative to support student's creativity that is very appropriate to apply to creative writing ideas and motivate students during presentations in higher education setting.
\end{abstract}

Keywords: Creative Writing, Presentation, and Focusky

\section{Introduction}

The development of technology at the end of the 20th century has been growing rapidly, especially in the field of education, media that supports the learning process more diverse, the number of application features that can be used in supporting the success of learning. This is also an opportunity for students to use the media more carefully in presenting the concepts that exist in every lecture assignment. The presence of various presentation media is expected to solve the biggest problem in every student discussion during lectures that is less noticed by other students. These issues has become a classic problem in the world of lectures today so it is necessary for a 
proper program for students to be able to solve the problem. It is known that many technology development programs can be utilized in presenting a concept but the usual presentation model will still not have much impact for students to be noticed by other students when presenting in front of the class.

Students have known very well a presentation program that is powerpoint, this program is good just not enough to attract the attention of students. It is necessary a program that can not only be used to display concepts but also be able to attract the attention of students while presenting. The program in question is Focusky, in addition to being easy to use the program is also able to display slide s tanyangan with zoom in-zoom out effect with friend facilities and object effects galore making this program very suitable if used by students in presenting their tasks in front of the class.

Focusky is a feature-packed presentation medium specially developed to create captivating presentations online as well as offline, presentations created can be shared over the web, while the operating system that can block this program is mac as well as windows. Thus, focusky can produce dynamic presentations that can be distributed to a number of users and can modify, personalize shapes according to their own needs. Focusky provides many templates that students can use to create presentations, although first-time use of the program will have no difficulty in creating presentations because it is very easy to use.

Based on the above exposure, making interesting presentation media is very helpful for students in completing various tasks given well. Therefore, we intend to apply focusky-based presentation media to the creative writing of students of the Faculty of Literature UMI.

\section{Focussky Presentation Media}

Media presentation according to Rahadi says (2008:4) is a message or material to be delivered that is packaged in a computer program and presented through a service device (projector). Packaged messages or materials can be text, images, animations, and videos combined in one whole unit. In line with these opinions, the advantages of presentation media in learning according to Kozma in Sutrisno (2009) are:

a. Presentation media can improve learning activities and can help students understand a material.

b. Presentation media can encourage students to think, engage, work together and express opinions.

c. The presentation is interesting because there are color games, letters and animations, whether it's text animation or image or photo animation.

d. It is more stimulating for the child to know more information about the teaching materials presented.

e. Information messages are visually easy for students to understand.

f. Educators don't have to explain much about the teaching materials that are being presented.

g. Can be reproduced as needed and can be used over and over again.

h. Can be stored in the form of optical or magnetic data. It'spractical to take anywhere. 
According to Amier (2010), presentation media has the following drawbacks:

a. High electrical current dependency.

b. The supporting media is relatively expensive because there must be a computer and LCD.

c. The use of this media depends heavily on the presenter of the material

d. There are still very limited teachers who are able to make

Focusky sangat is one of the programs to create very interesting presentation media with many advantages. Students are offered an alternative where they no longer need to use powerpoints that are paid and limited in the provision of templates. There is also no need to rethink the transition between slides because the ideas presented on focusky are more interesting with unlimited zoom and pan effects, focusky is able to display automatic 3D presentations because there are many features that support such facilities available in the form of templates (Fileeagle, 2018).

1. Free

Some of the advantages of focusky include the following.

2. Easy to use even for the first time

3. There are templates that are plentiful and can be used easily even if you're using the program for the first time.

4. Interesting zoom in and zoom out transitions

5. Complete writing and object effects available

6. Lightweight size even with standard laptop specifications.

Focusky can create presentations that contain different types of media such as images, videos, sounds, animations, formulas, graffiti, even charts provided as feature-fiutr in fokusky. A very complete and appropriate program for students in presenting assignments given in lectures even in other non-academic activities.

\section{METHOD}

This research is a descriptive qualitative study by conducting data collection through books and other literature as the main object (Hadi, 1995). According to Mantra 2008 Qualitative research produces information in the form of records and descriptive data contained in the researched text. With qualitative research, descriptive analysis is necessary. Descriptive analysis methods provide a clear, objective, systematic, analytical and critical picture and description of the application of focusky presentation media to the creative writing of university students. A qualitative approach based on the initial steps taken by collecting the required data, then classification and description are carried out. The reason the authors used descriptive qualitative methods in this study is because it is considered suitable for studying various references about presentasi focusky presentation media to creative writing by students.

Data sources in this study Buku and articles on media presentations and focusky programs as well as creative writing students. Metode used to collect research data in the form of literature data that has beenselected, searched, presented, and analyzed. The source of this research data is to look for library data whose substance blinds the processing action philosophically and theoretically. The library study here is a library study without empirical testing (Muhadjir, 1998). 
Data analysis is the stages in processing research data and developing it into a simple framework (Zed, 2004). The collected data is then selected and then analyzed to obtain the necessary information in accordance with the research problems (Mantra, 2008). In this study, using data analysis techniques in the form of content analysis. Content analysis is a scientific analysis of the content of a data message. So, as analysis materials and obtained from primary and secondary data sources are compiled to find the required data according to the research problems.

\section{RESULTS AND DISCUSSIONS}

Students are intellectuals who have many ideas and creativity that can be developed through proper education. There are many ways that students can channel ideas and opinion, creativity through writing.

Creative writing is part of the Indonesian language course. In this course, students learn how to write creative ideas through media. Media can be a creative way to be used in channeling creative and innovative ideas. Presentation media is the right role in conveying information or ideas either directly or indirectly because presentation media can be packaged in different types of messages.

According to Rahadi (2008) The content in a presentation media can be packaged in several types of files including text, images, animations, and videos combined in one whole unit. This shows that the presentation media can be delivered in front of a crowd directly or shared through cyberspace for the general public.

The development of presentation media from over the years is increasingly sophisticated along with the development of technology. Starting from presentations, projectors, and interactive whiteboards. While in terms of programs Microsoft office PowerPoint is the most popular program used today. Although paid, this program is available on all PCs or laptops that have a windows operating system.

Presentation programs continue to compete to appeal to their users. Each of these media has its own characteristics advantages. The presentation media program that is quite popular besides MS Powerpoint are prezi, emaze, googleslide, powton, sparkol and many more. Focusky program is one of the presentation media programs that has its own characteristic with the simplicity given to users in making presentations.

An interesting look with templates that swerp into added value that makes a beginner look like a professional in creating presentation media. In addition focusky can also be used for free which most previous presentation media programs are paid and used illegally by utilizing crack or keygen spread on the internet.

According to Fileeagle, 2018 uses focusky users do not have to rethink the transition between slides because the ideas presented on focusky are more interesting with unlimited zoom effects, focusky is able to display automatic 3D presentations because there are many features that support such facilities available in the form of templates.. With these advantages, this program is considered very suitable for students to make cool presentations and interesting presentation media. 


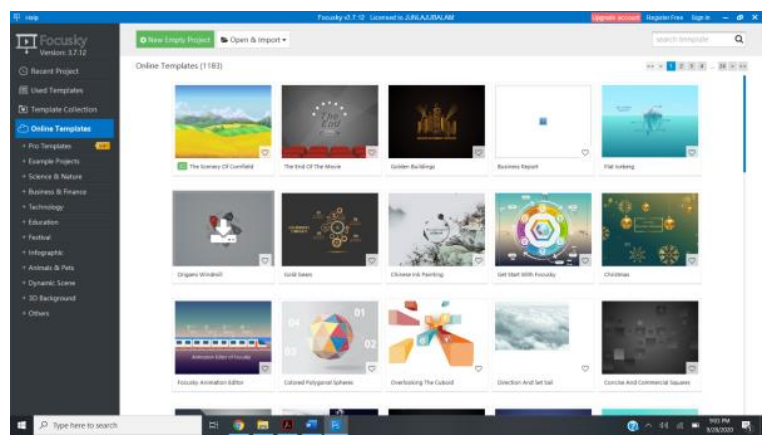

Figure 1. Focusky Template

The existence of cool and interesting elements will also support the ideas and ideas of students who will pour them in the presentation media. A cool and interesting template combination with a good idea will be able to produce a package of information that can be easily conveyed to the target information.

Students of the Faculty of Literature of The Muslim University of Indonesia are very interested in the world of creative writing. Various student ideas and ideas have been published in several printed media as well as online. However, there are still many other student ideas and ideas that have not been distributed. Therefore, the application of focusky presentation media on creative writing will help students in packing their ideas to be well received.

Students in general, for example at umi Faculty of Literature do not have the same information technology skills such as designing presentations. So, by utilizing focusky will help students who have the ability to make presentation media that previously quite became cool and interesting.

\section{CONCLUSIONS AND SUGGESTIONS}

Based on the findings, this study suggests that media presentations offer an interesting way to language learning particularly in writing skill. Focusky based presentation is very appropriate to apply to creative writing ideas for students of the Faculty of Literature, Universitas Muslim Indonesia. It is in line with Butler and Mautz (1996) concluded, based on a one class period experiment that students considered multimedia presentations entertaining. The present study expands Butler and Mautz (1996) in that it offers an alternative to PowerPoint presentations which are much simpler and varied. This study suggests that lecturers utilize focussky media presentation to minimize the difficulty in learning challenging materials since media presentation provides an interesting way to learn the materials. And students should develop themselves by self-taught to use various technologies for expressing ideas to follow the trends of the current globalized era.

\section{BIBLIOGRAPHY}

Amier. 2010.Presentation Media Development in Learning. Online. http://amierkamboja88.wordpress.com/2010/04/29/pengembanganmedia- presentationin-learning/. 
Butler, J. B., and R. D. Mautz, Jr. 1996. Multimedia Presentations and Learning: A Laboratory Experiment. Issues in Accounting Education (Vol. 11, No.2) 259-280.

Fileeagle. 2018. Focusky Software, (www.fileeagle.com/software/1981/fokusky-presentationmaker) [in access on March 2, 2019]

Hadi, Sutrisno. 1995. Statistics II. Jakarta. Pt. Rineka Cipta.

Mantra, Bagoes. Ida.2008. Philosophy of Research \& Social Research Methods. Yogyakarta : Student Library

Muhadjir Noeng. 1998. Qualitative Research Methodology. Yogyakarta: Rake Sarasin

Rahadi. 2008. Presentation Media Creation. Training Module. Online. http://widyo.staff.gunadarma.ac.id/Downloads/files/20317/10+pembuatan+media + presentation.doc

Sutrisno. 2009. Physics Subjects for High School (SMA)/Madrasah Aliyah (MA). Journal of Physics.Online.http://.upi.edu/Direktori/FPMIPA/JUR._PEND._FISIKA/195801071986 031-SUTRISNO/Layanan/Fisika.pdf.

Zed, Mestika. (2004) Library Research Method,Jakarta: Obor Foundation 